\title{
Development of Lemon and lime nectar at Mazoe Citrus Estate, Zimbabwe
}

\author{
Matiashe $\mathrm{I}^{1}$, Mahara $\mathrm{P}^{2}$, Marume $\mathrm{P}^{3}$
}

\begin{abstract}
The main objective of this research study was to develop a palatable ready to drink fruit beverage which will be acceptable to consumers using lemon and lime concentrates. The aim of this research project is to help reduce the large stores of lemon concentrate in stock at Mazoe Citrus Estate since this company had been facing challenges of fermentation and gelation of the lemon concentrate due to long term storage. Three lemon and lime nectar samples (sample A, B, C) containing different juice percentages were developed using both qualitative and quantitative research designs. Through sensory evaluation by a panel of 20 respondents from Mazoe Citrus, Midlands State University Food Science department and residents of Senga, the most preferred nectar sample was identified. Sample C, which was the most preferred nectar sample was then tested for brix, $\mathrm{pH}$, titratable acidity, pulp content, number of specks and microbes. The laboratory assessment results showed that the lemon and lime nectar conformed to the stipulated specifications of nectars and the lemon and lime nectar produced scored a shelf life of one month.
\end{abstract}

Keywords: - Beverage, Brix value, Nectar, Pulp

\section{INTRODUCTION}

Sutherland and Varnam(2000), defines nectars as fermentable but unfermented product obtained by the addition of water to fruit juice, concentrated fruit juice, fruit puree or concentrated fruit puree or a mixture of these that conform with the specifications and may contain up to 20\% added sugar. Marcos et al (2004) stipulated that nectars can contain preservatives, colorings and sweeteners. Bates, Morris and Crandall (2012), added that nectar should contain 20-50\% of the fruit juice though Marcos et al (2004) argues that nectar should contain pure juice ranging between $25-99 \%$ depending on the laws of each country. MCE standards for nectar are regulated by Standard Association of Zimbabwe (SAZ). SAZ (1994), points out that the minimum content of the single strength fruit ingredient or the equivalent from concentrated fruit juice ingredient shall be a mass fraction of not less than $15 \%$ of the nectar.

\section{Lemon and lime nectar}

The lemon and lime to be produced will be composed of lemon and lime concentrate, preservatives, sweetener, lime oil, flavor and water. Each of the ingredients will be included for different functions in the nectar.

\section{Health benefits of lemon and limes}

Chatham (2012) stated that lemon and limes have similar composition and nearly the same health benefits. He also explained the following health benefits of lemon and limes:

- Cancer prevention and treatment: the antioxidants present in lemons and limes are essential in the prevention of skin, lung, stomach, colon and mouth cancers. Limonin found in lemons and limes keeps cancerous cells from dividing.

- General health: vitamin C present in these fruits is essential in preventing heart disease, stroke and several cancers. Lemon and limes also participates in restraining and preventing malaria, colds and influenza. Lemons and limes are also known to balance body sugar, boost digestion and also help in burning fat.

- Rheumatoid arthritis protection : vitamin $\mathrm{C}$ can help prevent age related arthritis

Siddiq (2012) also added that lemon juice is a diuretic, which gives relief in bladder and kidney disorders. It is also essential in relieving gingivitis, stomatitis and inflammation of the tongue. He also goes on to say that limes have a therapeutic cooling effect in cases of fever and jaundice. Murray et al (2006) mentioned that limes and lemons have detoxifying and antibiotic properties which help in the healing of oral and peptic ulcers. The high potassium content of lemons and limes provides relaxation to the mind and body, controls blood pressure, nausea and dizziness. Ahmed, Lobo and Ozadadi (2012), presented the nutritional profile table of lemon s and limes below: 
Nutritional profile of lemons and limes.

\begin{tabular}{|c|c|c|c|c|c|c|}
\hline Nutrient & Units & $\begin{array}{l}\text { Raw lemon } \\
\text { without peel }\end{array}$ & $\begin{array}{l}\text { Lemon juice } \\
\text { canned/bottled }\end{array}$ & $\begin{array}{l}\text { Raw } \\
\text { lemon } \\
\text { peel }\end{array}$ & $\begin{array}{l}\text { Raw } \\
\text { lime }\end{array}$ & $\begin{array}{l}\text { Lime juice } \\
\text { canned/bottled } \\
\text { unsweetened }\end{array}$ \\
\hline$\frac{\text { Proximate }}{\text { Water }}$ & $\mathrm{g}$ & 88.98 & 92.46 & 81.6 & 88.26 & $\begin{array}{ll}.52 & 92\end{array}$ \\
\hline Energy & Kcal & 29 & 21 & 47 & 30 & 21 \\
\hline Protein & $\mathrm{G}$ & 1.1 & 0.4 & 1.5 & 0.7 & 0.25 \\
\hline total lipid & $\mathrm{G}$ & 0.3 & 0.29 & 0.3 & 0.2 & 0.23 \\
\hline carbohydrate & $\mathrm{G}$ & 9.32 & 6.48 & 16 & 10.54 & 6.69 \\
\hline Fiber & $\mathrm{G}$ & 2.8 & 0.4 & 10.6 & 2.8 & 0.4 \\
\hline Sugars & G & 2.5 & 2.4 & 4.17 & 1.69 & 1.37 \\
\hline$\frac{\text { Minerals }}{\text { Calcium }}$ & $\mathrm{mg}$ & 26 & 11 & 13.4 & 33 & 12 \\
\hline Iron & $\mathrm{Mg}$ & 0.6 & 0.13 & 0.8 & 0.6 & 0.23 \\
\hline magnesium & $\mathrm{Mg}$ & 8 & 8 & 15 & 6 & 7 \\
\hline phosphorus & $\mathrm{Mg}$ & 16 & 9 & 12 & 18 & 10 \\
\hline Potassium & $\mathrm{Mg}$ & 138 & 102 & 160 & 102 & 75 \\
\hline Sodium & $\mathrm{Mg}$ & 2 & 21 & 6 & 2 & 16 \\
\hline Zinc & $\mathrm{Mg}$ & 0.06 & 0.06 & 0.25 & 0.11 & 0.06 \\
\hline Copper & $\mathrm{Mg}$ & 0.037 & 0.037 & 0.092 & 0.065 & 0.03 \\
\hline manganese & $\mathrm{Mg}$ & 0.03 & 0.02 & $\mathrm{nr}$ & 0.008 & 0.008 \\
\hline Selenium & $\mathrm{Ug}$ & 0.4 & 0.1 & 0.7 & 0.4 & 0.1 \\
\hline$\frac{\text { Vitamins }}{\text { Vitamin C }}$ & $\mathrm{mg}$ & 53 & 24.8 & 129 & 29.1 & 6.4 \\
\hline Thiamine & $\mathrm{Mg}$ & 0.04 & 0.041 & 0.06 & 0.03 & 0.033 \\
\hline Riboflavin & $\mathrm{Mg}$ & 0.02 & 0.009 & 0.08 & 0.02 & 0.003 \\
\hline Niacin & $\mathrm{Mg}$ & 0.1 & 0.197 & 0.4 & 0.2 & 0.163 \\
\hline $\begin{array}{l}\text { Panthonthenic } \\
\text { acid }\end{array}$ & $\mathrm{Mg}$ & 0,19 & 0.091 & 0.319 & 0.217 & 0.066 \\
\hline Vitamin B6 & $\mathrm{Mg}$ & 0.08 & 0.043 & 0.172 & 0.043 & 0.027 \\
\hline Folate & Ug & 11 & 10 & 13 & 8 & 8 \\
\hline Choline & $\mathrm{Mg}$ & 5.1 & 5.1 & 8.5 & 5.1 & 5.1 \\
\hline Vitamin A & $\mathrm{Iu}$ & 22 & 15 & 50 & 50 & 16 \\
\hline cryptoxanthin & Ug & 20 & 13 & 45 & 0 & 0 \\
\hline Vitamin E & $\mathrm{Mg}$ & 0.15 & 0.15 & 0.25 & 0.22 & 0.12 \\
\hline Lutein+zeaxanthin & Ug & 11 & 11 & 18 & 0 & 0 \\
\hline
\end{tabular}

Adapted from Tropical and subtropical fruits by Ahmed, Lobo and Ozadali (2012)

\section{Chemical composition of lemon and limes}

Chemical composition of lemons and limes is almost the same and they differ in acid content since limes have higher acid content than lemons. Murano (2003) propounded that the lemon juice contains water, citric acid, phosphoric acid, melic acid which gives these fruits their sharp taste. Citral is an organic flavor component present in lemons and limes. Citronellol, pectin, hesperidin, d-limonene, sesquiterpene and phellandrene are other chemical components of lemons and limes.

\section{Microbiology of fruit nectars}

Byron (2004) defines microbiology as the branch of biology that deals with microorganisms and their effects on other living organisms. Microbial tests and experiment are carried out to understand factors that affect the growth of these microorganisms so as to come out with preservative measures that enable development of procedures to prevent the degradation of the quality of the nectar. Fruit juices are considered to only be susceptible to spoilage to spoilage by yeasts, mycelia fungi and lactic acid bacteria. Ito (2001) supported that the spoilage microorganisms of greatest significance in citrus fruit nectars the lactic acid bacteria primarily the lactobacillus and leuconostoc, yeast and moulds. Ray and Bhuna (2008) suggested that to prevent growth of these potential spoilage microorganisms, several additional preservation methods are used for the nectar which includes freezing, refrigeration and addition of specific preservatives. 


\section{Nectar quality}

Meloan and Pomeranz(2000), explained that the overall quality of the nectar can be grouped into three main categories that is quantitative, hidden and sensory. Other quantitative aspects of food quality are mostly of interest to the processor for example yield of product obtained from the raw material or of interest to both the consumer and the manufacturer for example ratio of more expensive to less expensive foods. Hidden quality attributes of foods include the nutritional value of food or the presence of toxic compounds that cannot be determined by sensory evaluation. Sensory quality

Sensory attributes of quality guide the consumer in his selection of foods. Such attributes are measured by the processor to determine consumer preference in order to manufacture an acceptable product at maximum production economy. Srilakshmi(2010), explained that the results from sensory testing are considered to represent the taste of the important portion of the population and so are used to foresee market outlook for a product. The test are also done to examine the influence of the factors in production and to detect the presence of off quality. Sensory attributes are also measured in determining the conformity of food with established government or trade standards and food grades. Meloan and Pomeranz(2000), added that the acceptance of a food is greatly determined by its sensory properties which is influenced by factors such as psychological factors, physical status of an individual, social factors, cultural factors and nutritional education. To minimize the effects of such factors, different procedures for sensory evaluation have been devised and the results are evaluated by statistical methods.

Laboratory tests may be conducted to:

- study human perception of food attributes

- to correlate sensory attributes with chemical and physical measurements

- evaluate raw material selection

- study processing effects on the product

- study the means of maintaining uniform quality to establish shelf life stability and reduce costs

- establish difference between samples and determine quality preference differences

Major sensory attributes in lemon and lime nectar are;

- appearance : colour, absence of defects and consistency of the liquid

- kinaesthetic : viscosity and consistency

- flavour : taste and odour

Color

Sutherland and Varnam (1999), stated that the color of the nectar should be typical of the fruit which it comes and this is why the lemon and lime produced is lime green in color. Meloan and Pomeranz (2000), noted that color is an important appearance factor in marketing. The color of a product often affects our perception of and evaluation by other senses. Discoloration or fading of color is often accompanied or identified by consumers as being associated with undesirable changes texture and flavor. In addition to color, transparency and turbidity are often important. Color standards and spectrophometric are used in determination of color. Mahindru (2008), stipulated that synthetic colors can be used to improve the color of food products. The synthetic colors may be classified into two that is the synthetic color dyes and the mineral pigments. The color of the produced lemon and lime was enhanced by the addition of approved synthetic color dye, fast green (FCF) which exist as dark green powder or granules with metallic shine and can readily dissolve in water.

Taste

There are four basic modalities sweet, sour, salt and bitter and these are perceived by receptors on the tongue. Sugar may enhance or depress the perception of sourness. In the production of lemon and lime nectar, since lemons and limes are high in acid, sugar was added to enhance the taste of the nectar. Meloan and Pomeranz (2000) stipulated that taste sensation and thresholds are affected by several factors such as the beverages temperature, the overall juice composition, and concentration of individual components and the age of the consumer. The lemon and lime nectar tastes best when served chilled. Measurement of total soluble solids helps in determining the taste of the product. Computing the ratio between parameters also helps to determine the taste of the product for example sugar-titratable acidity ratio is required to establish an acceptable correlation with sensory evaluation.

\section{Flavour}

Flavour is the sensory impression of foods and beverages and is mainly determined by the chemical senses of taste and smell. The senses which detect chemical irritants in the mouth and throat as well as temperature and texture are also important to the overall flavor perception. The flavor of food and beverages can be enhanced by natural or artificial flavorants. Siddiq (2012) stated that flavorant refers to the edible chemicals 
and extracts that alter the flavor of food and food products through the sense of smell. Due to high cost or unavailability of natural flavor extract most commercial flavorant which are chemically equivalent to natural flavor but chemically synthesized are usually used. The citral which is an organic flavor component contributed to the flavor of the nectar. Murano (2003), citrus flavorings are derivatives of the aromatic principle of fruit of the citrus family. Flavoring is compounded from the oils of citrus fruit which is obtained from the skin of the citrus fruits. Lemon oil and chemically synthesized lime flavor were used to enhance the flavor of the lemon and lime nectar. Subbulakshmi and Udipi (2001) stated that when processing lemon juice beverages, bitterness retention of flavor is a common problem and this effect is minimized by the use of citrus oils.

\section{Appearance}

Besides color, taste and flavor of the nectar, the kinaesthetic properties such as viscosity and consistency of the nectar also affect the acceptance of the nectar. Stabilizers are used to maintain the stability of the nectar. Mahindru (2008) mentioned that alginates are stabilizers that are used in fruit juice powders and fruit drinks. Sodium alginate is an example of an alginate stabilizer that is used in fruit juices. Stabilizers prevent the formation of ice crystals during process of freezing and they produce uniform viscosity. So stabilizers improve the quality of the nectar by maintaining the desirable viscosity and consistency.

In this research the experimental design was used which according to Somekh and Lewin (2009) involves the manipulation of at least one independent variable to see whether or not it has any impact on the dependent variable. In this research experiments were used to determine the $\mathrm{pH}$, titratable acidity, microbial content and the brix level of the nectar.

\section{MATERIALS AND METHODS}

\section{Qualitative research design}

Since subjective human feelings are difficult to quantify, qualitative analytical methods can be used and these methods take more account of the soft personal data, Walliman (2011). This qualitative research approach was used in this research by assessing the sensory attributes of the nectar such as taste, flavor, mouth feel and color. This was accomplished by the use of a questionnaire whereby the respondents would be asked to write down how they feel about each sensory quality attribute of the product.

\section{Population of the study}

In this research the population of the study includes the MCE staff, student at Midlands State University (MSU) and other residents of Senga who took part in sensory evaluation. The lemon and lime concentrates used in the production of the nectar also make up population under study.

\section{Sample size}

- Number of respondents to the questionnaire -20

- Sample A of the nectar-20samples

- Sample B of the nectar - 20 samples

- Sample C of the nectar -20 sample

\section{Sampling and sampling techniques}

\section{Judgmental sampling}

In this research judgmental sampling was used in the selection of raw materials. The samples have been distinguished by their different lime and lemon juice percentage content as shown in the table below.

\section{Lemon and lime nectar samples prepared.}

\begin{tabular}{|l|l|l|l|}
\hline Sample & Lime juice \% & Lemon juice \% & Total juice \% \\
\hline A & $5 \%$ & $20 \%$ & $25 \%$ \\
\hline B & $5 \%$ & $15 \%$ & $20 \%$ \\
\hline C & $5 \%$ & $10 \%$ & $15 \%$ \\
\hline
\end{tabular}

\section{Random sampling}

After getting the concentrate samples by judgmental sampling, random sampling was used in carrying out the laboratory tests to verify the specifications of the concentrates.

\section{Stratified random sampling}

Stratified random sampling is another sampling technique which was employed in this research. In this research population was divided into three strata that is the MCE quality assurance team, MSU students and the residents of Senga Gweru and random sampling was used to select respondents from the strata. Stratified sampling guarantees that every element in the population has a chance of being selected and when they are 
properly designed, they more accurately reflect characteristics of the population from which they were chosen than other techniques.

\section{Research Tools}

The tools that were used in this research are laboratory experiments and a sensory evaluation questionnaire.

\section{Laboratory experiments}

Brix value determination

Specification: 12-13

$\mathrm{pH}$ value determination

Specification: 3.5- 4.5

\section{Titratable acidity determination}

The mixture was titrated using $0.1562 \mathrm{NAOH}$ to a faint pink endpoint. The percentage titratable acidity is calculated using the formula below:

$\%$ titratable acidity $=$ titre $/$ weight

Specification: $0.35-0.5$

\section{Pulp content determination}

The pulp level on the centrifuge tube was read halfway between the highest and the lowest level of the pulp sedimentation and the pulp \% was calculated as shown below:
$\%$ pulp $=$ volume of pulp $\times 100 \% / 10 \mathrm{ml}$ of the sample

Specification: 5-40\%

Hesperidin evaluation

Specification 18-20

Microbial tests

Specifications

Yeast and moulds- less than 10 per gram

TPC (orange serum agar)- less than 100 per gram and nil for coliforms.

\section{Questionnaire}

A questionnaire was used to assess the overall acceptability of the nectar by preparing samples of the nectar and asking the respondents to taste the nectar and fill in the questionnaire. The hedonic scale was also included in the questionnaire. This is a scale that indicates the extent of respondents overall liking or disliking for something.

III.

\section{DISCUSSION}

RESULTS AND

\subsection{Sensory evaluation results}

The three nectars produced sample A, B and sample C were given to 20 respondents who participated in sensory evaluation by filling the questionnaires and the following results were obtained.

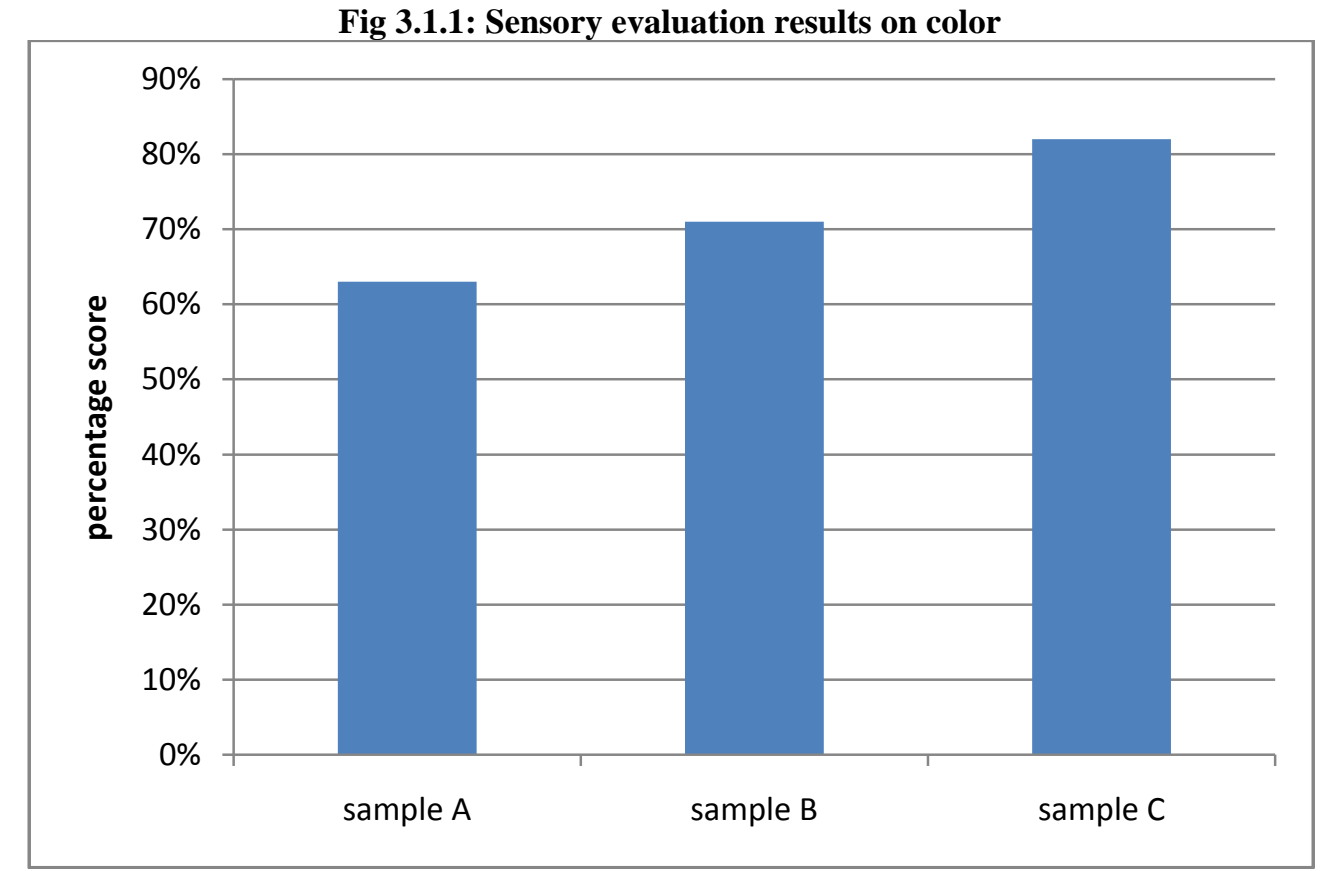

Sample C's color was the most preferred having the highest score of $82 \%$. Sample A scored $63 \%$ which was the least and sample B scored $71 \%$. 
Fig 3.1.2: Sensory evaluation results on taste

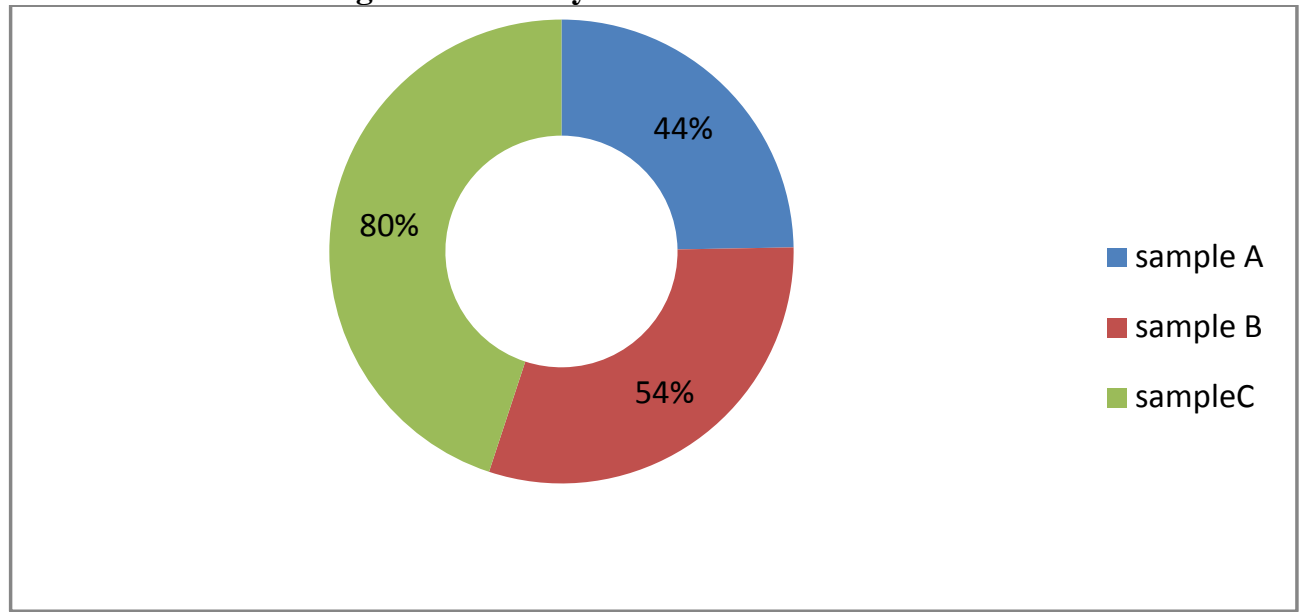

The taste for sample A was poor as it scored 44\%, the taste for sample B was average scoring 54\%. The most preferred taste was sample $\mathrm{C}$ which scored $80 \%$ and there is a very big difference in taste between sample A and sample C.

\section{Fig 3.1.3 Sensory evaluation results for flavor}

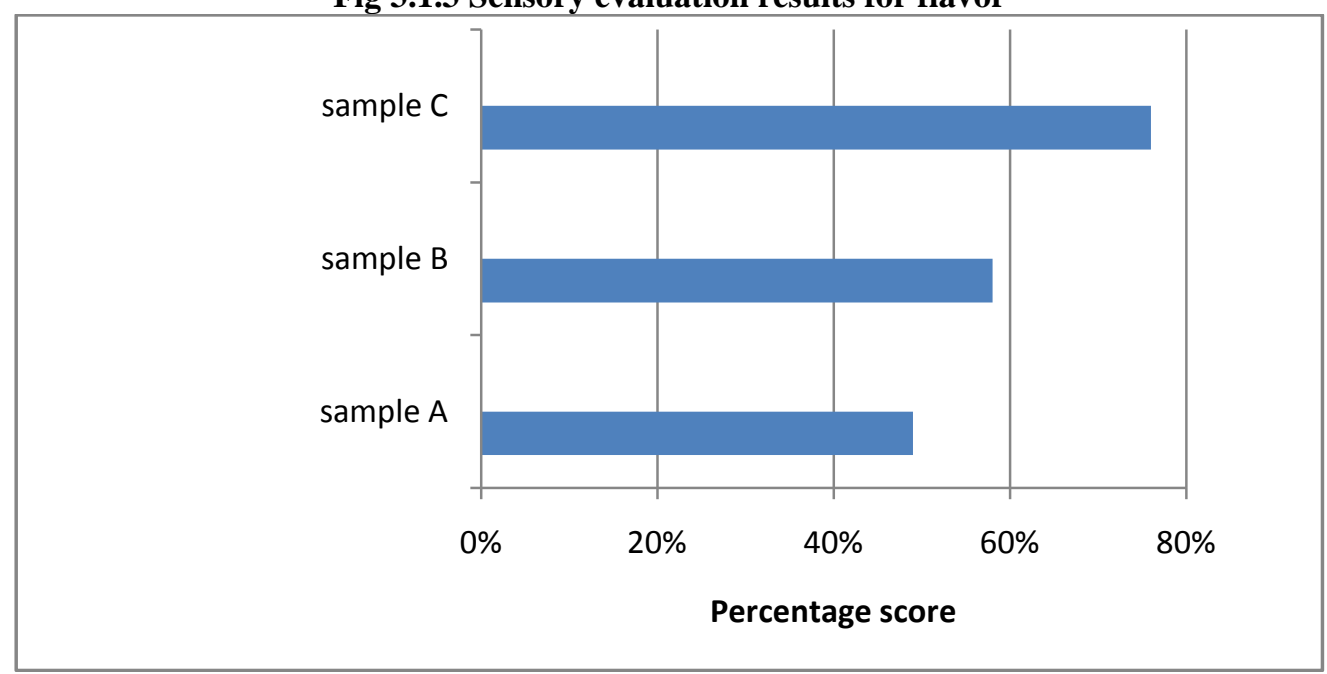

Sample A scored the least, 49\%, sample B scored 58\% and sample C scored $74 \%$. Sample C had the most acceptable flavor. There is a big difference between sample A and sample $\mathrm{C}$ meaning to say the flavor of sample A was generally poor and the majority of the test panel disliked it.

\section{Fig 3.1.4 Sensory evaluation results for mouth feel results}

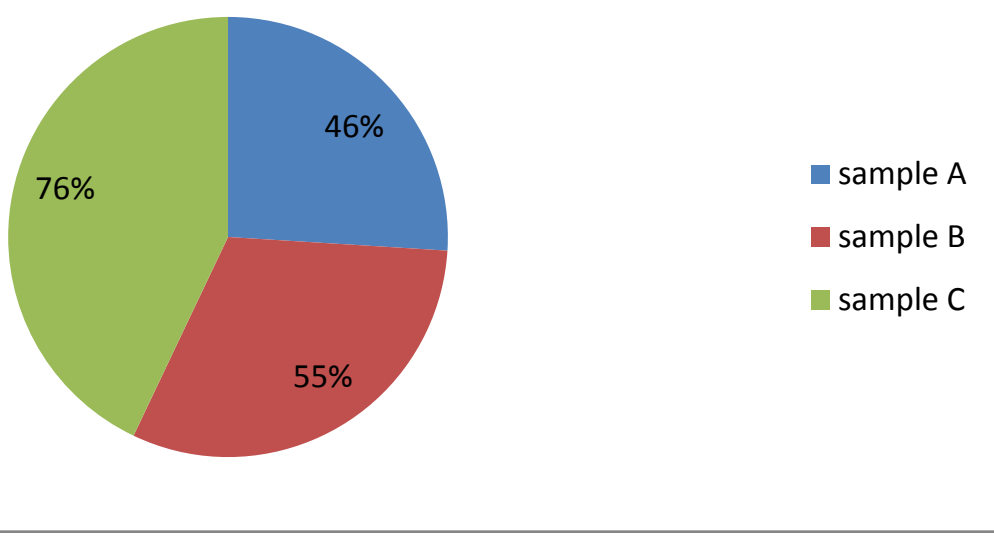


Mouth feel refers to a complex sensory attribute encompassing feeling and trigeminal impulses of texture, heat, coolness, sponginess, lubricity, sliminess, chalkiness, etc. the mouth feel of sample A was generally undesirable scoring $46 \%$. The mouth feel for sample B was good scoring 55\% and sample C had the most desired mouth feel scoring $76 \%$

Fig 3.1.5 Sensory evaluation results for the most preferred sample

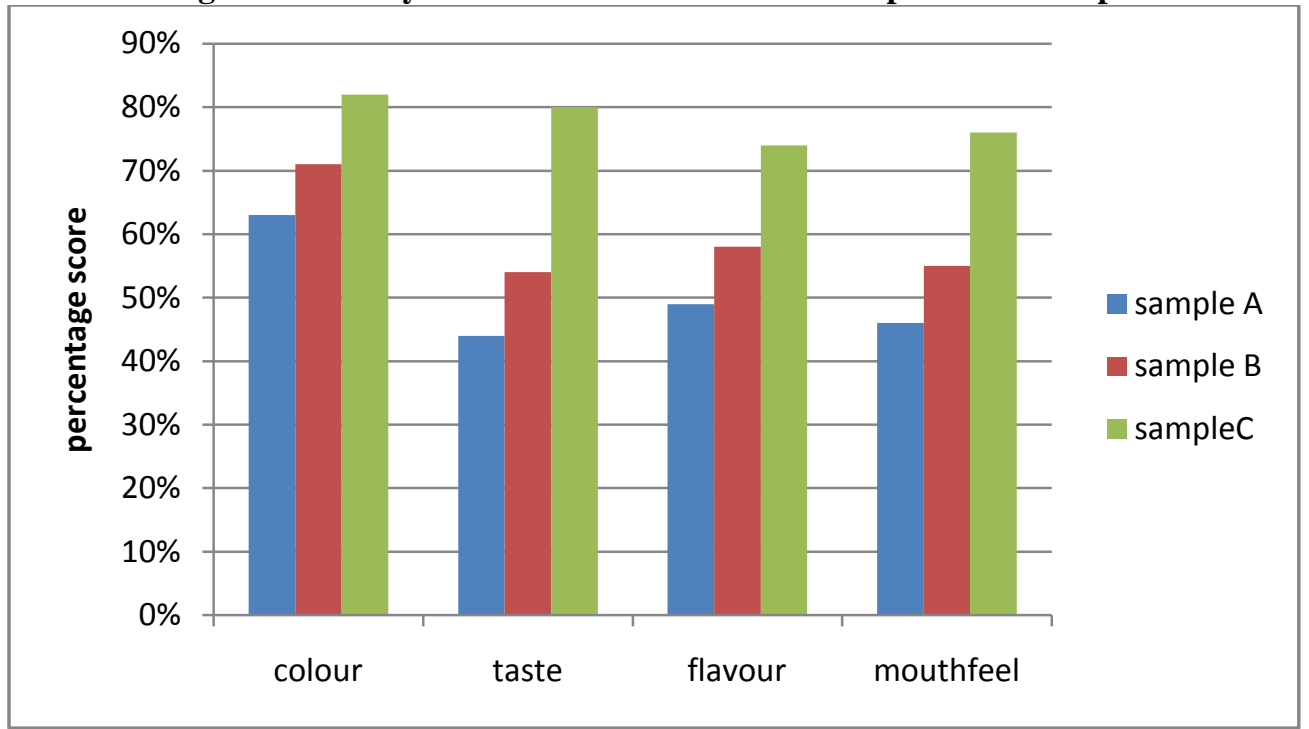

The graph illustrate that the most preferred nectar was sample C, followed by sample B then the least preferred was sample A.

The table below shows the results on the ranking of the samples in numerical order according to preference starting with the highest that is the most preferred sample:

Table 1: Preference ranking for the nectar samples

\begin{tabular}{|l|l|}
\hline Preference & Sample \\
\hline 1 & C \\
\hline 2 & B \\
\hline 3 & A \\
\hline
\end{tabular}

\subsection{Laboratory assessment results}

Sample C was the most preferred lemon and lime nectar which contained $15 \%$ of the real lemon and lime juice. Laboratory tests were carried out for its shelf life analysis, brix value, pulp content and to analyze its microbiological quality.

USDA hesperidin speck count -18

Pulp content $-4 \%$

Fig $3.3 \mathrm{pH}$ results

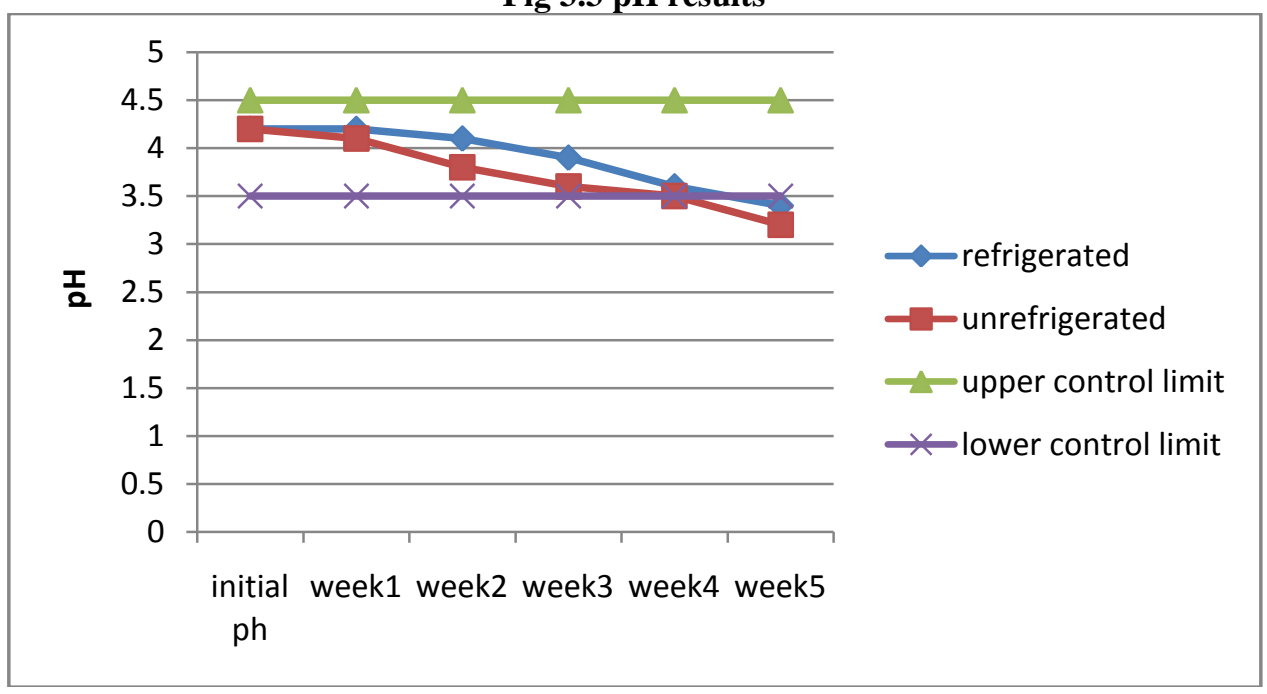


Fig 3.3 shows the comparison of $\mathrm{pH}$ change in refrigerated nectar and unrefrigerated nectar. This was done in five weeks to determine the effect of cold storage on the lemon and lime nectar. The initial $\mathrm{pH}$ value that was recorded on the day of manufacture was 4.2 and the $\mathrm{pH}$ value decreased with time.

Fig 3.4 Brix value results

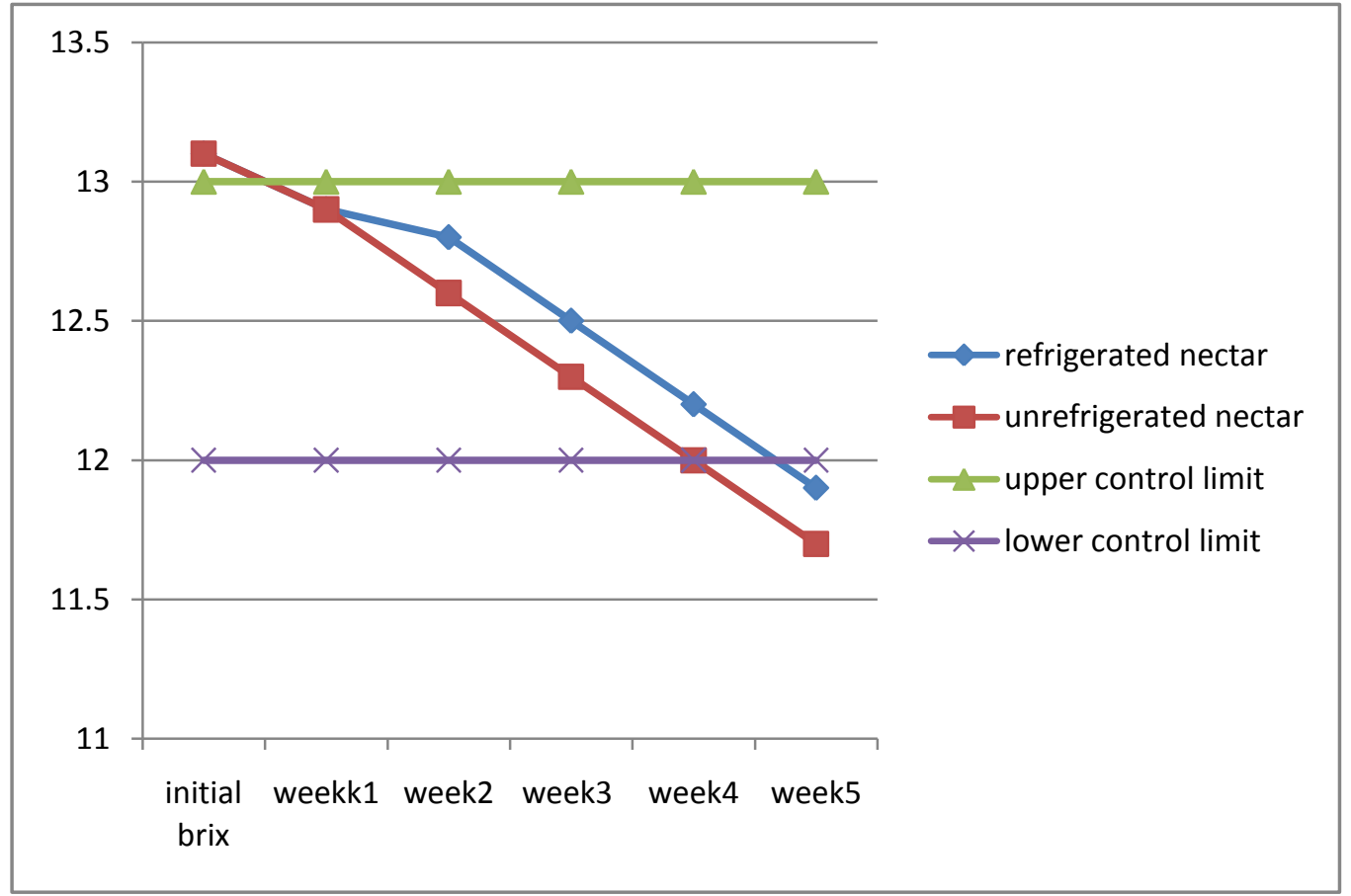

Brix value is the measurement of the total soluble solids. Meloan and Pomeranz (2000) stated that the measurement of the total soluble solids helps in the determining taste of the product. The results show that the brix of the nectar decreased with time. There was a rapid decrease in brix value of the unrefrigerated nectar than in refrigerated nectar.

Fig 3.5 Titratable acidity results

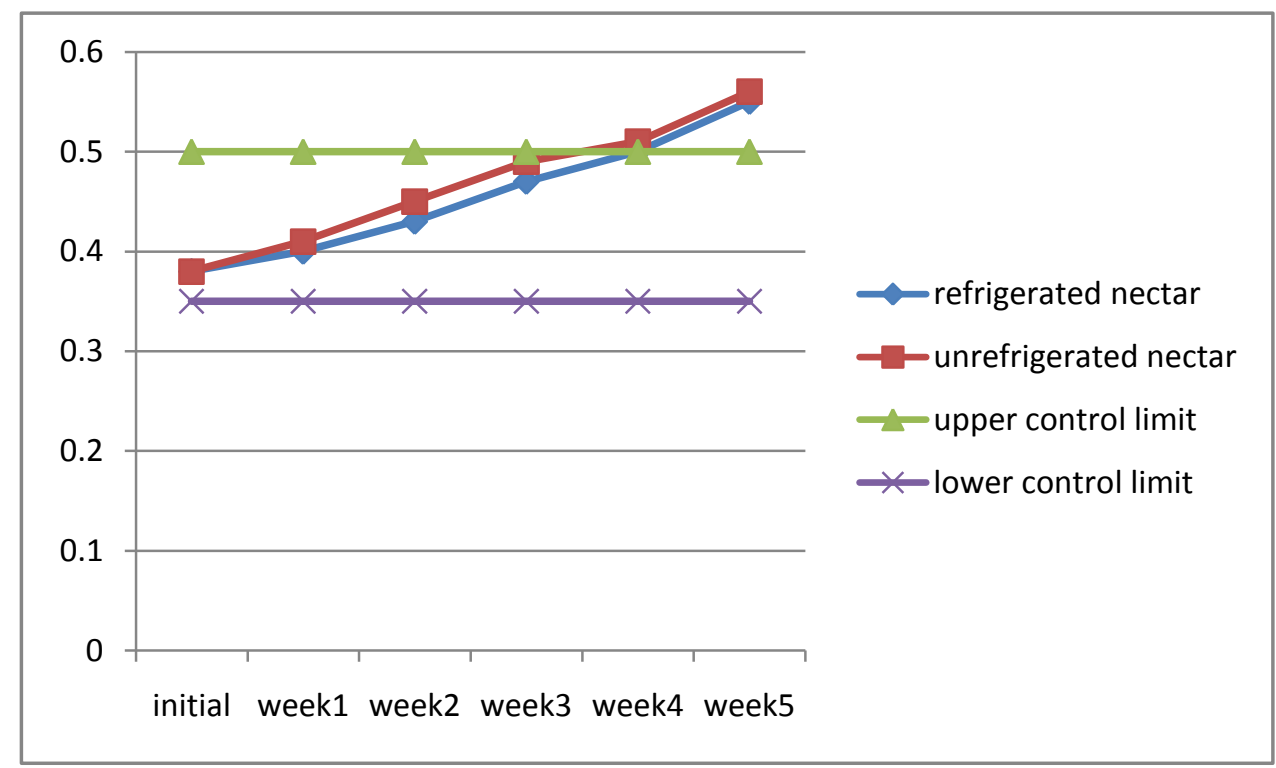

The titratable acidity of the nectar both refrigerated and unrefrigerated increase with time. The rate of increase in titratable acidity of unrefrigerated nectar is higher than that of the refrigerated nectar.

3.6 Microbiology results 
Fig 3.6.1: Results for yeasts and moulds

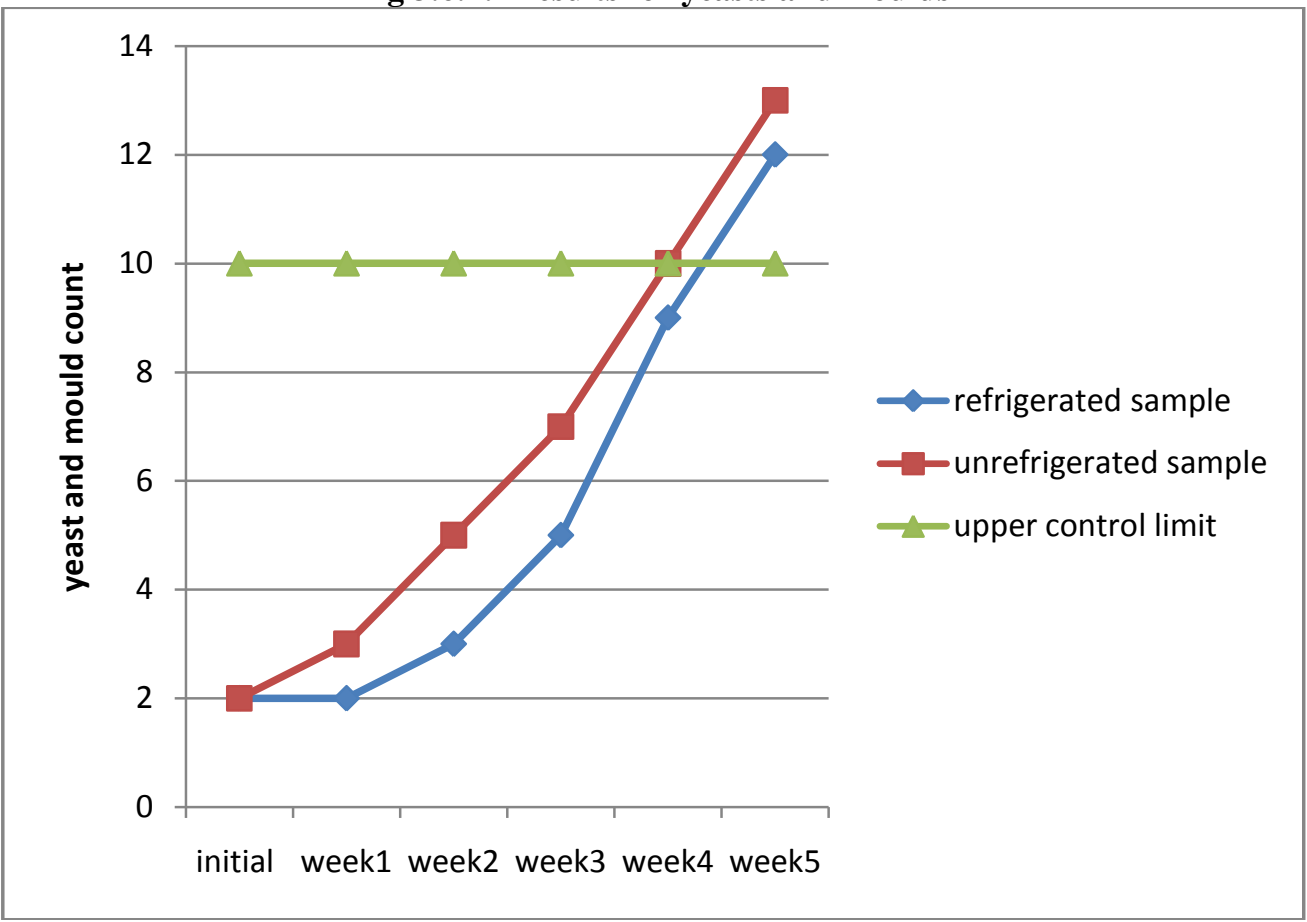

The yeast and mould count in both refrigerated and unrefrigerated nectar increased with time. At week5 the yeast and mould count showed a deviation from the range of specification since it was above 10 .

Fig 3.6.2 Results for bacterial count

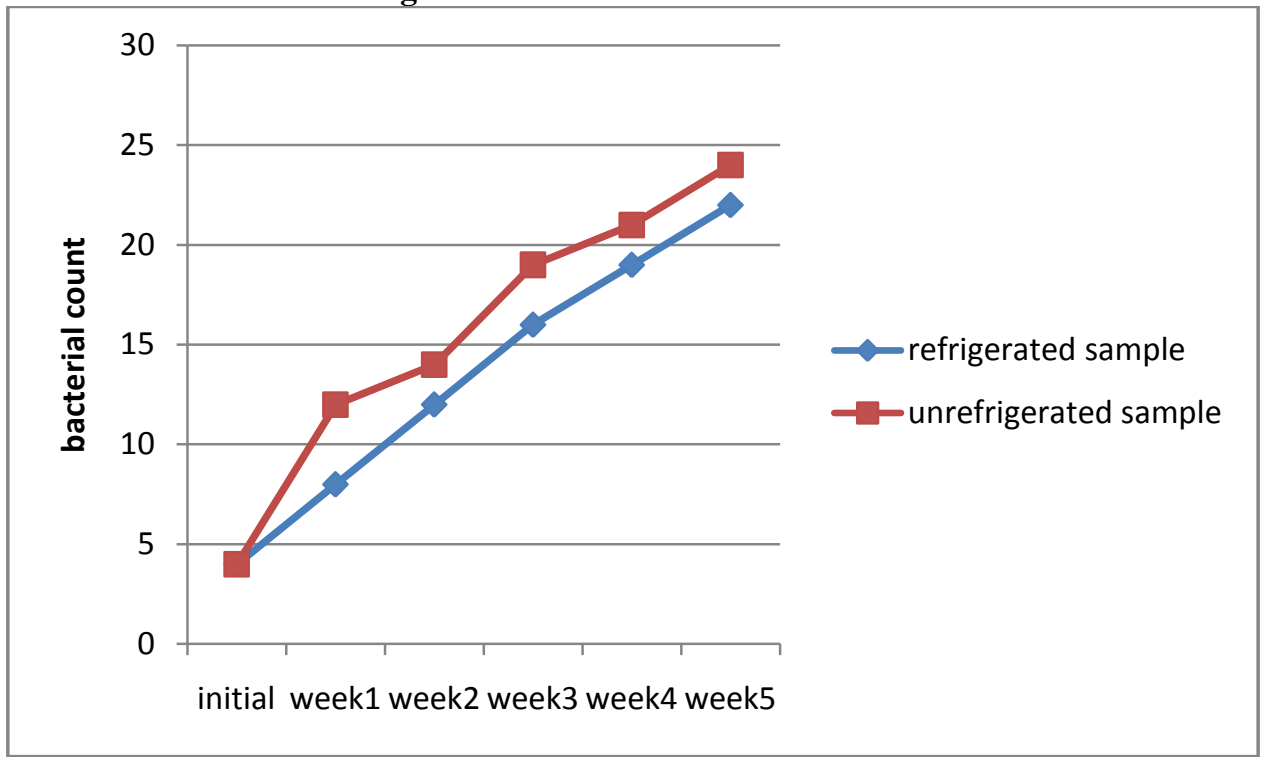

The fig shows that generally the number bacteria present in the nectar were generally low since it was within the specification, less than 100 per $\mathrm{ml}$. The graph shows that number of bacteria present in the nectar increased with time and the rate of growth and replication was faster in unrefrigerated sample than in refrigerated sample. This was due to growth and replication of the bacteria.

Table 2: Results on Ecoli and coliforms

\begin{tabular}{|l|l|}
\hline E coli & Nil \\
\hline Coliforms & Nil \\
\hline
\end{tabular}

The absence of coliforms and Ecoli indicates that the nectar is safe for human consumption. 


\section{Shelf life}

Nectar was analyzed and monitored for the parameters $\mathrm{pH}$, brix, titratable acidity, yeasts and moulds over a period of five weeks. The results for these parameters for both refrigerated and unrefrigerated nectar presented a deviation from the range of the specification at week 5 . This means the product will be unfit for consumption from week 5 and afterwards. The recommended shelf life of the nectar will be placed at 4 weeks thus one month and it should be kept refrigerated.

\section{CONCLUSION}

The research study was successful since the researcher managed to produce microbiologically safe lemon and lime nectar which had a good consumer acceptance and its parameters were within the range of nectar specifications of MCE. Statistical analysis concluded that there is a significant difference in consumer preference between lemon and lime nectars with different juice percentages and there is no significant difference in shelf life between refrigerated and unrefrigerated lemon and lime nectar.

\section{REFERENCES}

[1] Ahmed Jasim, Lobo Maria G and Ozadadi Ferhan (2012), Tropical and Subtropical Fruits: Postharvest physiology Processing and Packaging, Wiley Publication, USA

[2] Ahurst P.R(2000),Production and Packaging of Non carbonated fruit juices and fruit beverages $2^{\text {nd }}$ Edition, Aspen Publication, New York

[3] Bhattacharyya D K(2004), Research methodology $1^{\text {st }}$ Edition, Excel Book Publisher, New Delhi , India

[4] Breakwell Glynis M, Hammond Sean and Fife-Shaw Chris(2006), Research Methods in Psychology $3^{\text {rd }}$ Edition, Sage Publishers, London

[5] Byron (2004), A Drinking Life: A Memoir, Little, Brown and Company New York

[6] Chatham J (2012), A Complete Guide To Juicing: juice for weight loss, health and life, Calisto Publishers , USA

[7] Jay James M, Loessner Martin J, Golden David A (2005), Modern Food Microbiology $7^{\text {th }}$ Edition, Springer Science Publishers, USA

[8] Lean M,E, J(2006), Food Science Nutrition and Health $7^{\text {th }}$ Edition, Arnold Publishers, London

[9] Mahindru SN(2008), Food Additives, characteristics, detection and estimation, APH Publishing Corporation, New Delhi

[10] Marwaha SS and Arora JK,(2000),Food Processing, biotechnological Application $1^{\text {st }}$ Edition, Asiatech Publishers, India

[11] Meloan CE and Pomeranz Y, (2000), Food Analysis: theory and practice $3^{\text {rd }}$ Edition, Aspen Publication, New York

[12] Murano Peter S (2003), Understanding Food Science and Technology, Wadsworth Learning Publishers, USA

[13] Murray M T, Pizzorno J, Lara Pizzorno (2006), The condensed encyclopedia of healing foods. (books, google.co.zw/books)

[14] Ray Bibek and Bhuna Arun (2008), Fundamental Food Microbiology $4^{\text {th }}$ Edition, CRC Press, USA

[15] Srilakshmi B (2010), Food Science $5^{\text {th }}$ Edition, New Age International Publishers, New Delhi.

[16] Sidel J L, Stone H and Bloomquist J. (2007), Use and misuse of sensory evaluation in research and quality control. Tragon. USA

[17] Smith Jim and Charter Edward (2011), Functional Food Product Development, Wiley Publication, USA

[18] Subbulakshmi G and Udipi Shobha A (2001), Food processing and preservation, New Age Publishers, USA

[19] Walliman N (2011), Your Research Project $3^{\text {rd }}$ Edition, Sage Publishers, London 